\title{
AurkA inhibitors enhance the effects of B-RAF and MEK inhibitors in melanoma treatment
}

\author{
Emilia Caputo ${ }^{1 *}$, Roberta Miceli ${ }^{2}$, Maria L. Motti ${ }^{3}$, Rosarita Taté ${ }^{2}$, Federica Fratangelo ${ }^{2}$, Gerardo Botti ${ }^{2}$, \\ Nicola Mozzillo², Maria V Carriero ${ }^{2}$, Ernesta Cavalcanti ${ }^{2}$, Giuseppe Palmieri ${ }^{4}$, Gennaro Ciliberto ${ }^{2}$, Giuseppe Pirozzi ${ }^{2}$, \\ Paolo A Ascierto ${ }^{2}$
}

From Melanoma Bridge Meeting 2014

Naples, Italy. 03-06 December 2014

\section{Background}

Aurora Kinase A (AurkA), one of the key regulators of $M$ phase progression, is over-expressed in melanoma and has been observed to limit tumor growth $[1,2]$. The potential use of this molecule as target for biological therapy in melanoma has been examined.

\section{Materials and methods}

A375mel (BRAFV600E) melanoma cell line was used in this study. The cell line was exposed to B-RAF inhibitor (GSK2118436), MEK inhibitor (GSK1120212) and AurkA inhibitor (MLN8054) as single agents or in various combinations (B-RAF plus AurkA inhibitor, MEK plus AurkA inhibitor) or in triple combination (B-RAF plus MEK plus AurkA inhibitor).

The effects on the cell growth of drugs, used as single agents and as different combinations, were examined by the $x$ CELLigence technology. Total protein extracts were examined for p53 and c-myc protein expression by Western Blot analysis. The drug's efficacy was also tested by using a 3D-human melanoma skin reconstruction model.

\section{Results}

A375 (BRAFV600E) melanoma cells treatment with AurkA inhibitors in combination with B-RAF and/or MEK inhibitors alone and/or with both B-RAF/MEK inhibitors, increased the anti-tumor efficacy of the drugs than given as single agents.

The AurkA inhibitors enhancing anti-melanoma effect on B-RAF and MEK inhibitors was furthermore

${ }^{1}$ Institute of Genetics and Biophysics -I.G.B., A. Buzzati-Traverso-, CNR, Naples, Italy

Full list of author information is available at the end of the article confirmed in a 3D-human melanoma model, where it was restricted to a melanoma cell sub-population localized at epithelial/dermal junction site. However, S-100 and Ki-67 positively stained spindle-shaped cells were detected in the dermal stratum, suggesting the presence of alive and proliferating melanoma cells.

\section{Conclusions}

These findings provide new prospects for melanoma research. For the first time, based on these results, it was observed that the triple combination treatment was more efficacious as anti-melanoma therapy. Interesting, the treatment was efficacious only on polygonal-shaped melanoma cells present at the epidermal/dermal junction site as small nests, while spindle-shaped melanoma cells present in the dermal stratum remained alive and proliferating. This finding suggested that these cells may account of the drug resistance and so be responsible of disease recurrence later on. Molecular characterization of these dermal cells may be critical for the development of novel therapeutic strategies.

\footnotetext{
Authors' details

${ }^{1}$ Institute of Genetics and Biophysics -I.G.B., A. Buzzati-Traverso-, CNR, Naples, Italy. ${ }^{2}$ Istituto Nazionale Tumori Fondazione G. Pascale, Naples, Italy. ${ }^{3}$ Dipartimento di Scienze Motorie e del Benessere, Università di Napoli 'Parthenope', Naples, Italy. ${ }^{4}$ Unit of Cancer Genetics, Institute of Biomolecular Chemistry (ICB-CNR), Sassari, Italy.
}

Published: 15 January 2015

\section{References}

1. Vader G, Lens SM: The Aurora kinase family in cell division and cancer. Biochim Biophys Acta 2008, 1786:60-72.

2. Nikonova AS, Astsaturov I, Serebriiskii IG, Dunbrack RL Jr, Golemis EA: Aurora A kinase (AURKA) in normal and pathological cell division. Cell Mol Life Sci 2013, 70:661-687. 
doi:10.1186/1479-5876-13-S1-P1

Cite this article as: Caputo et al:: AurkA inhibitors enhance the effects

of B-RAF and MEK inhibitors in melanoma treatment. Journal of

Translational Medicine 2015 13(Suppl 1):P1.

Submit your next manuscript to BioMed Central and take full advantage of:

- Convenient online submission

- Thorough peer review

- No space constraints or color figure charges

- Immediate publication on acceptance

- Inclusion in PubMed, CAS, Scopus and Google Scholar

- Research which is freely available for redistribution

Submit your manuscript at 